\title{
Governance Approach in Asia's Third Sector: Adapted Western or Modified
}

Asian?

\section{INTRODUCTION}

In the $21^{\text {st }}$ century there are 50,000 international NGOs worldwide, some with grassroots engagement. There are also about 7,000 microfinance institutions (MFI) in the world serving 16 million people. There are hundreds of thousands of small, traditional, non-incorporated organisations that remain largely undocumented. Since the WWII the developed world has provided US\$2300 billion in international aid, and at present around $10-20 \%$ of the annual ODA of US\$60b is disbursed through the third sector. Further, many Asian governments have been providing tacit supports in the expansion of philanthropy and the third sector, and also in improving the latter's capabilities for strategic benefits. The growth and functioning of the third sector and its contribution to development, however, depends on the stage of political infrastructure of the country concerned (cf. Davis and McGregor, 2000). There are vibrant and numerous TSOs in Asian countries, but due to a weak political infrastructure their impacts on development in these countries are likely to be minimal.

In recent times the third sector has been growing rapidly in many countries, even in China. During the preparation for UN Conference on Women, the term 'NGO' was popularised in China (Ma, 2001). These NGOs are “issue-oriented social groups, rather than interest groups or pressure groups" (Zhao, 2001) ${ }^{\mathrm{i}}$. States, like China with a centrally controlled system under Party apparatus, may not be able to contain the growth of the third sector organizations, thus each state now allows TSOs to become partners in societal governance and the state, in turn, influences TSO governance.

The six Asian countries that participated in our study have a strong and varied third sector. Despite differences in the culture, politics and recent history of these six countries, there was more variation within the third sector of each country than there was between countries. In each country we found large and small TSOs in each of the fields of activity we had in our focus. Other studies suggest that TSOs will vary in the importance of their contribution to particular fields but they will be found in each field in each country. ${ }^{\text {ii }}$ The same story holds for the governance of TSOs. Once again 
there was considerable variation in the practice of governance within TSOs in each country but rarely did one country stand out from the rest for the presence or absence of a particular practice.

One of the questions that motivated this study was whether there was a common Asian approach to the governance of third sector organisations. In fact, given the huge differences in history, culture, political systems and level of economic development, we did not expect to find a common approach to the governance of third sector organisations across Asia. However, there were those who talked of an Asian way in conducting political relations while others criticised an Asian approach to the governance of corporations, so we sceptically reviewed our evidence to see if we could detect a common approach. So what have we learned from this research project?

Our basic conclusion is that governance is important, but deals with a difficult and contradictory set of tasks and responsibilities. There is no "one best method", but rather a set of questions that each organisational leadership group needs to answer in order to ensure their organisation is balancing the interests of its key stakeholders (members, clients, or patrons) as well as it can. This Chapter, by summarising and highlighting some contentions, attempts to answer our original question: is there an Asian approach to governance of TSOs? A related question by the many advocates of a corporate governance model: how does the corporate governance model play out on the ground?

We begin the chapter with a review of the concept of "governance" within Asian TSOs. We then re-examine the legal and legislative space within which Asian TSOs operate. Following a review of the northern corporate governance model, we then try and identify specifically, what are the criteria of "good governance" in Asian TSOs. Grappling with this question leads us to our final conclusions, which we see, not as an end point, but as the identification of unanswered questions, and the need for further research into the governance of Asian TSOs, the role of governments and of external funding bodies. 


\section{IDENTIFYING“GOVERNANCE” FOR OUR CONTEXT}

The term governance is widely used by political leaders and policy makers and in the social science research community. It is not a term that is widely understood, even in those Northern countries that have done so much to advance its use. Our national collaborators found it difficult to translate "governance" into their respective languages. Rule seemed the closest English term that was easily translatable. It is also understood as just “governing” or in most cases, “internal management”. Even then we found a great deal of variation in the understanding of governance and of who in the final analysis was responsible for it. This was as true among the organisational executives that provided the data for our organisational survey as it was for the social and political leaders that we interviewed for their knowledge of parts of the third sector. It appeared that for the men and women in their positions, the more common discourse on societal governance created puzzlement about the application of the concept to TSOs. Once again, while more of our interviewees in some countries shared the conventional understanding of the term than in others, this difference did not appear significant. Significant was the borrowing of the value position "good" appended to societal governance literature (or norms?) by the World Bank and others. The authors of Chapter Four thus comment that "the emphasis on the evaluative (good governance) aspect rather than on the descriptive (governance) issues in the Asian TSO governance may be because the Asians in general are (value) judgmental”. This value position seems to be the defining factor not only in the understanding of TSO governance- in its application as well.

\section{THIRD SECTOR LEGAL SPACE AND APPLICATION IN THE PARTICIPATING COUNTRIES}

It is evident from the study that the devolved third sector 'territory' (eg. in China, Thailand, Vietnam) opens-up slowly but remains steady more than the evolved system like our other three participating countries (India, Indonesia, and the Philippines). In the latter case, the trial and error approach creates distrust between the government and the TSOs. In any event, however, the legal instruments in all countries are reactive (problem shooting), and not proactive engaging instruments. Thus two major criteria that we discovered are: purposive ambiguity and freedom restraining intentions in the legal documents none of which can improve governance. 


\subsection{Purposive Ambiguity}

We have seen a very restrictive third sector legal environment in Thailand, but the study revealed evidences of politicisation of TSOs in Thailand. The highly centralised political system in Thailand legitimises the control of the TSOs' activities, but then the elite centered or created TSOs are straightforwardly accepted and legalised. Thus the laws become more ineffective due to the double standards and discriminatory practices of the State Agencies (Anukansai and Boonrad, 2003). The problem also may be related to the social hierarchy as many of the elite (or even officials) find it unacceptable that an elite's program, organization, or activity is turned down, monitored, or chased by an official who has a lesser social status (Vichit-Vadakan, 2006).

Indonesia seems to have a different problem. In Indonesia TSO laws are activitybased, and thus overlapping. For example, an association and a mass organisation, both are member-based, but regulated by different laws. Associations in Indonesia are loosely regulated entities and are under the jurisdiction of Civil Law ${ }^{\text {iii }}$ because they are non-political. On the other hand, mass organisations (the so called "embryonic political parties", also known as social organisations) are regulated by Law no. 8 of 1985, and are closely monitored by the ministry and the local administration ${ }^{\text {iv }}$ (Radyati and Fadjr, 2003). The problem is that the Law No. 8, gives the Minister of the Interior powers over mass organisations, which the Ministry interprets to cover all civil society organisations (Irish, 2003).

One of the major problems related to the legal environment regulating the TSOs in China is that it is based on executive documents (without any approval from the People's Congress) or even oral ruling ${ }^{\mathrm{v}}$ or unpublished documents that the TSOs may not be aware of. Some experts on Chinese law have pointed out that expecting the NGOs to follow regulations that are not legally coded or explicit or well known is an unlawful practice (Su, Ge, Zhang, and Gao, 1999, 43). If the government suddenly decides to act against the NGOs, the NGOs may not have any redress. The governments in countries like China, Indonesia, or Thailand nurture vagueness in laws and the procedure, to have the upper hand on the TSOs, if needs be. This is not helpful in the establishment of good governance in the TSOs. 


\subsection{Growth Centered Vs Freedom Restraining Legal Environment}

A country's laws, regulations and their administration can both help and hinder the growth and sustainability of the third sector. Governments, with the help of the legislative frame, related to the incorporation, taxation, fundraising and service standards and their administration can assist the third sector by recognising the distinct character of the third sector, facilitating its good governance, and encouraging public support. The legislative frame should also consider sustainability issues by regularly updating the laws and regulations to suit contemporary theory and principle. A well functioning and supportive legal environment is of little value if the wider policy environment is hostile, or indifferent to the third sector.

TSOs in many nascent democracies have been involved in judicial activism to fill in the legal gap in the functioning of the TSO or defining their stakeholder relationships including with the beneficiaries and the government. For example, during the last quarter century, TSOs in India have made tremendous contribution to bridge the gap between constitutional aspiration and social reality (Bhatt, 2003). The legal environment is thus gradually evolving to expand the "space" for the third sector but becoming ineffective because of the executives' disinterest in accepting and applying the judicial imposition (though legally binding).

The law becomes more appreciating and effective when the government, on its own accord, establishes a congenial relationship with the TSOs valuing the latter's activities as complementing the government's efforts. In such a situation stringent governmental measures influencing internal as well as external organisational dynamics of the TSO, as seen in the case of the Philippines, for example, can be seen in good spirit and not as adversarial. ${ }^{\mathrm{vi}}$

The fact that a large percentage of the respondents in China identified political change to be essential for impacting the third sector's development suggests the interfering nature of politics. The Chinese government has a different approach to monitoring the TSO activities requiring all private nonprofit units or non-government noncommercial enterprises with three or more CCP members to establish party branches to supervise the organisation's political behavior. ${ }^{\text {vii }}$ Further most social organizations in China are dependent on the government, and have a governance pattern influenced by the government. Priority in China, according to many respondents, thus is not to 
promote governance for the third sector, but to create a friendly legal environment for the third sector. Many foundations in Indonesia (commonly known as LSM) see the provisions of the Foundation Law 2000 as "too much interference towards the internal organisation of foundations", and re-registering as 'associations' a better option to escape "Foundation style” monitoring (Radyati and Fadjr, 2003). To be effective, the laws need to be practical and encouraging the "good" while still restricting the bad practices.

\section{THE INFLUENCE OF THE NORTHERN CORPORATE GOVERNANCE MODEL}

When we turn to the arrangements and practices of governance we find most TSOs had a board and in most cases this board had the final say in the organisation. Our overall impression is that while there is a greater degree of variety in practices (a greater deviation form a norm) than might be found in a similar survey of TSOs in English speaking Northern countries, the majority of organisations differ little in their arrangements and practices of governance.

We conclude that the large number of common elements in the arrangements and practices of TSO governance in our six participating countries is a product of the broadly similar approaches of the colonial governments of most (and the imitation of European arrangements in the country that was not colonised for example China). ${ }^{\text {vii }}$ The colonial regimes set the basic legal frameworks that post independence regimes mostly had little political interest or economic rationale to change. Overall, as our countries sought to join global markets and accept Northern technologies and cultural offerings, Northern practices of TSO governance, especially those in the United States, came to reinforce and in some cases modify existing practices. The two countries that adopted communism as part of their struggle for independence did suppress their third sector for several decades but in their subsequent opening they have sought to imitate Northern models of civil society, albeit with a little more control than is presently exercised in those model regimes. The opening up coincides with these two countries reform programs that began in the 1980s; thus the adoption of the Western model is more a declaration of "joining the club" than appreciating the norms. In some other cases it seems to be an imposition. 
There is a good deal of convergence between approaches to governance advocated for corporate and third sector organisations. Indeed, the most generally advocated model for third sector governance is often called the corporate governance model. This is not surprising as in the common law countries company law tends to have a large influence on legal forms used to incorporate third sector organisations.

There is however another legal form that influences thinking about, and practice of, the governance of both firms and third sector organisations: the trust. The governors of a trust, including a charitable trust, are the trustees (a term used in the UK to describe directors of many different types of third sector organisations). The responsibility of trustees is to preserve the trust and ensure it is applied to its founding purpose. Practices derived from the governance of trusts underpin two important components of the corporate governance model. One is the emphasis on what is referred to as the fiduciary responsibilities of directors; the second is the practice of the board determining who will replace retiring board members.

Within the third sector, the corporate model of governance argues for small boards with directors selected to bring a wide range of management or business skills to the board, and thus to the governance of the organisation. Boards of most big nonprofits are comprised mainly of people with senior management experience in business or government. Generally directors are unpaid. If the third sector organisation is also a charitable trust, the law may require that the directors are "trustees" and be people of high repute and standing in their communities. They also appoint independent auditors, but to save money these are generally asked to do the minimum level of audit required by law. There is no equivalent of independent analysts, whose reports can be drawn on by members or donors.

When we look outside the confines of economically developed common law countries, we can see other cultural and political dimensions that would certainly challenge the assumptions built into the corporate governance model and make its applications questionable.

One such set of dimensions are cultural. This set of possible differences encompasses not only the obvious differences in religious tradition, but also differences in what Hofstede (1991) has called power distance and uncertainty avoidance. In some cultures patron-client arrangements are what enables the society to work; in some 
cultures, uncertainty and thus risk taking is to be avoided. Both of these characteristics, if present will inevitably alter the way organisations are governed, and make the split-power arrangements built into the corporate model even more difficult to apply.

A second set of assumptions taken for granted by the corporate model of governance concerns the political system. The countries wherein it has emerged are among the oldest democracies in the world, where there are widely shared understandings of the role of political parties, legislators, the executive, administrators and courts. They are countries with low levels of corruption. In such countries third sector organisations can assume a high level of independence of government interference, provided they stay within what is generally a well-articulated legal and regulatory framework. Such assumptions cannot be made in most Southern countries where the political system is being made or re-made, where the legal and regulatory environment is more fluid and where corruption is an ever-present factor.

\section{SO WHAT ARE THE CRITERIA OF GOOD GOVERNANCE IN ASIAN THIRD SECTOR ORGANISATIONS?}

Governance is important, but deals with a difficult and contradictory set of tasks and responsibilities. There is no "one best method", but rather a set of questions that each organisational leadership group needs to answer in order to ensure their organisation is balancing the interests of its key stakeholders (members, clients, or patrons) as well as it can. Nonetheless, we explored several major themes that, in Asian eyes at least, are regarded as essential ingredients of a well performing third sector organisation

\subsection{Arrangements and Practices of Governance}

Most TSOs had a board (87\%) and in most cases this board had the final say in the organisation. One important thing resonates from the data: in many respects governance is effective when the board has the final say in the organisation. In our sample TSOs with effective boards (with final say) enhance mutual cooperation, and lead to better performance. Eighty three percent of such TSOs coordinate with other TSOs as opposed to $68 \%$ and $67 \%$, respectively, when the CEO or the members have the final say. Again $70 \%$ of the TSOs where the board has the final say (as opposed to 
$59 \%$ of the CEO-dominated and 38\% of the member-dominated board) are involved in representation to the government in matters other than fund raising.

Effective boards can help perform better by developing better political relationships to negotiate 'political system'. For example, whereas only $44 \%$ and $43 \%$ of the TSOs where the CEO or the members (respectively) have the final say, the TSOs are involved in negotiating the political system for the organisation. But the political negotiation is much higher (61\% of the TSOs) where the board has the final say in the organization. Further, effective boards (with final say) help high achievement by reviewing the organisation's performance more (67\%) than the others (43\% in case of CEO controlled board or $46 \%$ in member-controlled board). Effective boards (with final say) lead to better attainment by quality assurance, and evaluating efficiency. For example, quality assurance is undertaken more (59\%) in the board controlled organizations than in the others (41\% in case of CEO controlled board or $43 \%$ in member-controlled board), and board evaluates efficiency more (73\%) than the others (49\% in case of CEO controlled board or $57 \%$ in member-controlled board) where the board has the final say.

Three more features need to be available for good governance for third sector organisations: transparency, accountability, and financial sustainability. Across the region, 79\% of organisations do have some sort of system for measuring performance. A formal financial procedure is followed by $93 \%$ of organizations across the region, with no significant variation by country. Overall, 82\% of organizations prepare a budget. The board reviews and approves the annual financial statements in $71 \%$ of organizations. Overall, $88 \%$ of organizations report its activities outside the organization, and for $80 \%$ of organisations, this includes an annual report.

\subsection{The importance of Values and Social Capital}

All country reports emphasised the importance of values in the maintenance of good governance. Third sector governance, to many of the respondents in India, emerges from the human values of justice, and self-check and thus means being accountable to one's conscience (Dongre and Gopalan, 2006). People working in the TSOs in Thailand must have integrity in their professions since they work with the disadvantaged and may be tempted to indulge in corrupt practices to serve selfinterests even with the public funds. The TSOs themselves are vigilant of each others behaviors and have developed mechanism for dealing with deviation of integrity 
(Vichit-Vadakn, 2006). Self-discipline that creates and implements a very strict management regime has been important for many TSOs in China (Ding, 2005). For many respondents in the Philippines, TSO governance is adhering to the values of integrity, social responsibility, and social consciousness in personal and organisational behavior (Domingo, 2006). The organisational respondents in Indonesia believe that governance must involve high ethical and personal moral (Radyati, 2006). Personal integrity, moral uprightness, and self-discipline help understand TSO governance but are also features that allow individuals social legitimacy in collective life, and help achieve the common good. This emphasis on personal integrity is particularly important for the driving force, or the patron in the patron/client model, as much depends on his or her trustworthiness.

Other common espoused values concerned the maintenance of smooth interpersonal relationships and a spirit of trust and co-operation. Indonesia and the Philippines in particular emphasized the importance of mutual support within the local community and within the organisation itself. The idea that an organisation is only "good" to the extent that it contributes to civil society reinforces the contention that third sector governance enhances social capital. Smaller organisations are in a much better position to create and use social capital than the larger ones. Large bureaucratically structured organisations have minimal decision making input from the members or client/customers. Large bureaucracies hinder the creation of social capital, as do those that maintain any sort of vertical coercive sanctions. This is so because vertical structures generate dependent relations that discourage reciprocity and mutuality, in which choice is absent, and trust depends on the good will of the powerful (Onyx, 2003).

\subsection{Discussion}

Despite the wide presence of boards and good management practices, fewer than 6\% of our sample adopted the full corporate model of governance, and only another $17 \%$ a slightly modified version of it. These facts at first glance may be surprising, given the large amount of emphasis to this model in the normative literature on the third sector, including the policy statements and recommendations of Northern governments and international agencies. Evidence that these practices had been 
absorbed by the third sector was provided by their adoption by the third sector accreditation regimes that had been formed in the Philippines and India. However, it would appear that most TSOs find it difficult or perhaps unnecessary to go the whole way.

Three aspects of current arrangements stand out: the limited extent to which our TSOs had adopted the model of corporate governance mandated as good practice by many commentators; the limited extent to which TSOs practiced democratic forms of governance and the strange impact of foreign funders on governance practices. We will reflect briefly on each of these in turn.

First, it is clear that the corporate model of governance is not self evidently the only effective approach to governance of any form of organisation. The corporate model is based on a body of economic theory. It is designed to address a particular relationship, that between owners and paid staff (or principle and agent) that is problematised within that theory. It is not clear that it works well (Ghoshal 2005). There are alternative ways of identifying the problems in the relations between boards and staff (Blair and Stout 1999). Other models (for example those with two or more boards) operate with good effect in many Northern countries (Turnbull 2001). The model creates an inevitable tension at the heart of board practice: between its risk adverse fiduciary duty and its role of ensuring the organisation is pursuing the strategies needed to enable it best to realise its mission. It therefore makes sense that our sample organisations should adopt those aspects of corporate governance theory which appear to inform good practice in the Asian context, but avoiding those which do not.

In addition to a democratic decision making process, three more features need to be available for good governance for third sector organisations: transparency, accountability, and financial sustainability. A major requirement for all these is financial reporting and making financial accounts available to the public. In many cases, however, economic aspects cannot be identified and analysed because of the secrecy surrounding it in Asian third sector organisations. The secrecy is for the donors genuine desire to remain anonymous from the belief that revelations may be tantamount to showing-off and jeopardize the "merit". From the organizational donors' (local as more significant than overseas) perspectives low publicity can create less demand on their resources, and they can then pursue their agenda, if any, with a select few TSOs at the receiving end. Our partners in India, Indonesia, and the Philippines 
confirmed this fact. In certain cases, some interviewees threatened to abandon the interview should the interviewer insist on questions like sources and size of funds or reporting mechanism. In an earlier work from the Philippines, Aldaba (2003) found out that though $90 \%$ of the surveyed NGOs were registered with the Securities and Exchange Commission, most did not fulfil the government's requirements of annual reporting. Non-transparency and elite centricity in TSOs (mainly due to the founder's connections) undermines accountability.

Second, If TSOs are to be part of and to help build civil society within their respective countries then it is particularly important that they practice their members in democracy. It is worth noting that only $12 \%$ of our sample or $18 \%$ of organisations in our sample that had members actually practiced democratic forms of governance. These were more likely to be identified as good performers and to be accountable to a wider public. In the context of building social capital and a strong civil society, this failure of democratic process is significant and of major concern. It is likely that more participatory democratic processes are entailed, for example in the small informal non-incorporated organisations such as the Indonesian Arisan or the Indian village guilds. However, democratic practices are largely lacking in the larger, formally incorporated TSOs of our sample. This is particularly striking in the context of the dominant driving force, where a dominant patron made most of the decisions. Indeed the patron/ client model is not conducive to the construction of social capital or democratic processes. Bonding social capital generated in homogenous organisations (eg. caste-based organizations in India) may be stronger than that in heterogeneous organizations; the other side of the social capital coin is its exclusionary impact. Thus development of social capital within a narrow base may have a negative effect on the generation of social capital across the wider community. Further, apparent social capital generated in a hierarchic society, dominated by the powerful patron(s) and where the people at the lower social strata accepts the "ill" as a given is also not helpful in TSO governance, or the wider community. Further, apparent social capital generated in a hierarchic society where the people at the lower social strata accepts the "ill" as a given is also not helpful in TSO governance.

During authoritarian regimes, TSOs are seen as opposition, and social activism is discouraged, irrespective of the governance relationships. The contention is true even 
for party-dominated system of China and Vietnam where the TSOs have been allowed to grow because of their non-intervention in political structure and/or ideology. As a result of their movement in a relatively unguarded legal space, the TSOs have self selected membership, and representation, and almost no competition of (or challenge to) ideas and/or leadership. Thus a large number of the TSOs that claims to be using a democratic model, in fact demonstrate no competition among ideas and/or leaders. Third, the role of foreign funders is an important, and not always positive one. When we began this study we imagined that we would find a strong correlation between organisations that were at least partly dependant on foreign funds and good corporate governance model. After all, some of them were amongst the strongest proponents of the view that to strengthen civil society required strengthening the third sector. Some at least appeared as champions of the corporate model of third sector governance. We did indeed find some supporting evidence for this. The presence of foreign funding in Asian TSOs meant that it was more likely to be incorporated, to have a board, and to practice good financial and accountability practices. On the other hand we also found that TSOs that had a dominant driving force, that is, that failed to follow either a corporate or a democratic model of governance, were significantly more likely to be dependant on foreign funds. TSOs with a democratic model of governance were significantly unlikely to receive foreign funds.

The encouragement of democratic governance should be espoused by those international agencies that have contributed so much to the growth of a strong third sector in our six countries and still exercise a considerable influence, far broader than their financial writ. But our findings about the role of foreign funders suggest that they will have to change a good deal before they encourage the good practices and outcomes that they espouse.

Five TSOs were working as sub agents for larger TSOs, which would take all the decisions pertaining to the course of action and assign the implementation work to these TSOs. Thus, these are nothing but the paid agencies for discharging the work for others, like a paid labour force on contract. As against this trend, most (93\%) of unincorporated organizations ${ }^{\mathrm{ix}}$ have been found to be working in a single chosen functional area. This fact indicates a possibility of the TSOs moving towards the functional areas for which funding is available, rather than focusing on a particular 
area of their concern and strength. Unregistered/informal initiatives do not look for outside funds and hence are more committed to and focused on a single activity.

\section{CONCLUSIONS}

In the recent past, the third sector has been growing steadily all over the world. There are two important aspects related to third sector organisations that call for better governance, control and efficiency. Donor countries and international organisations are emphasising more third sector involvement in overseeing state activities. So third sector organisations should set their homes in order first. Second, with the dying up of overseas funds third sector organisations will have to depend on indigenous funds. The more credible the third sector organisations are, being efficiently managed, the more likely they are to raise more funds.

The research found that there is a movement toward the corporate model of governance. Though there is little clear thinking about governance in any of the six countries, there is a basic acceptance that a third sector organisation must have a board and that board plays an important role in its governance. There is a wide spread acceptance of many of what would be classed as good practice governance and management in Western countries, but the complete model is only followed in a few cases. There are two reasons for this isomorphism; one is the mandating of board model of governance in almost all pieces of legislation incorporating third sector organisations. Some of these date back to colonial times. But the pressure to adopt more complete "good governance” practices is strongly driven by the international funding agencies. There is a significant link between good governance practices and being recognised as a well performing organisation, even after size is taken into account. However this is particularly true of the larger economically significant organisations. In a few of our six countries there are still many organisations that are run on traditional lines, in other cases there are still vestiges of traditional practice. There is some evidence of a life cycle; organisations are dominated by a founder for the first decade or two and have weak ineffective boards but as the organisation grows and as the founder moves out of the driving seat, the conventional forms of governance become more important.

Asian third sector organisation governance is seen to be concerned with formulating, reviewing, and realizing the TSO's vision, mission, and goals. This relates to decision-making processes and structures involving the board, leader, and staff. Democratic governance in the TSOs is thus about good intentions for an equitable 
outcome by the CEO, leader, or the members, and not about policy making by the democratically elected board. Democratic or good governance in the TSOs appears not to be about means (ie. by the people), rather it is about the ends (ie. for the people).

In summary, then, it appears clear that the corporate model of governance, whether in its corporations' governance version or its nonprofit/third sector version, is far from being self-evidently the best model available. So why is it being pushed onto third sector organisations in the South by government aid agencies, the OECD, and private foundations, both grant-making and technical support providing?

The answer to that question is probably for the same reasons that the corporate model of governance is being urged for Southern companies as well. The Northern advocates have funds to invest (or to grant) and feel a great deal more secure if the recipients of these investments (grants) behave in ways they are familiar with. This may also explain their preference for a charismatic driving force with whom they have developed a personal relationship. As well, they stress the importance of transparency to make their work of judging whether their funds have been applied to the organisations mission and determining the success of that mission, that much easier.

There are two other reasons why the corporate model and particularly one of its key attributes, transparency, is being urged on third sector organisations in the South. Both are to do with the claims that parts of the third sector make to be the voice of civil society. Supra-national governmental agencies such as the World Bank that have accepted these claims and wish to use these organisations to keep their governments honest necessarily have to insist that the third sector models transparency in their governance. Others, including some Southern governments and third sector organisations representing business interests, frequently claim that these third sector organisations wield far more power than their narrow constituency base warrants. They argue for third sector transparency, especially of membership numbers and processes to demonstrate constituency support for positions advocated. Interestingly, as noted above, organisational democracy is not a matter of great interest to advocates of the corporate model. 
So, to end with a question, should the corporate model of governance be advocated as the best and most appropriate form of governance for third sector organisations, whatever their purpose and wherever they are found?

The answer to that question can only be: no, at least not until we know a great deal more about the way third sector organisations actually are governed in different countries.

We need to know a lot more about the way, in different Southern countries, deepseated cultural factors affect the governing of organisations. In all countries there is a tradition of collective voluntary action, and forms of third sector organisation that are hundreds, even thousands of years old. How have these adjusted to the forces of modernisation and globalisation? Do assumptions and practices deeply embedded in a nation's culture still impact the governance of even organisations introduced from Northern countries, such as the Red Cross/Red Crescent? We need to know more about the way the institutions of the law affect organisations, not only the formal statutes but also the extent to which, and manner in which, they are enforced. We need to know, too, about the way governments interact with third sector organisations, not only through legal and administrative processes but also the sorts of rules and practices attached to funding and the ways various forms of corruption might affect the operation of organisations. We need to know whether and how officials of political parties and local power brokers create a difficult environment for third sector organisations and the various methods they use to negotiate these difficulties.

Finally, we need to know these things for the variety of third sector organisations and not just the few big NGOs that are the recipient of most international aid, nor the radical movements of peasants or tribal peoples or urban workers organised to resist a dam or to seek justice for their people. We need to look over the range of third sector organisations: the temples/mosques and churches, the village associations and credit associations, the farmers and workers cooperatives, the religious schools, the health centres and hospitals, the business and professional associations and unions, the environment groups, the development NGOs and so on.

Clearly, in any country there will be many forms for governing third sector organisations and practices surrounding these forms. Rather than seeking to impose a particular form of governance generally on the third sector, it seems sensible first of 
all to study what is there, and to seek to discover if there are relations between particular governance practices and organisational performance.

\section{References}

Edwards, M and D. Hulme (1996). Beyond the Magic Bullet: NGO Performance and Accountability in the Post-Cold War Period, Kumarian, West Hartford, CT.

Edwards, M. and D. Hulme (1992). Making A Difference: NGO and Development in a Changing World (London: Earthscan Publications Ltd.).

Riggs, Fred (1975). The Ecology of Public Administration, Asia Publishing House, London.

Smillie, I. And J. Hailey (2001). Managing for Change: Leadership, Strategy, and Management in Asian NGOs (London: Earthscan).

Tandon, R. and R. Mohanty (2002). Civil Society and Governance, Samskriti, New Delhi.

White, S.C. (1999). 'NGOs, Civil Society, and the State in Bangladesh: The Politics of Representing the Poor', Development and Change 30:307-26.

Carver, J. 1997 Boards That Make a Difference: A New Design for Leadership in Nonprofit and Public Organizations. Second Edition. San Francisco, Jossey-Bass.

Herman, R. D. and Heimovics, R. D. 1991 Executive Leadership in Nonprofit

Organizations: New Strategies for Shaping Executive-Board Dynamics. San

Francisco, Jossey-Bass.

Hofstede, G. 1994 Cultures and Organizations: Intercultural Cooperation and its Importance for Survival. London, Harper Collins.

Blair M. and Stout L. (1999) “A Team Production Theory of Corporate Law” Virginia Law Review 85 (2) 247- 328.

Ghoshal, S. (2005) “Bad Management Theories Are Destroying Good Management Practices” Academy of Management Learning and Education, 4 (1) 75-91.

Turnbull, S. (2002) A New Way to Govern: Organisations and society after Enron. London, New Economics Foundation. 


\footnotetext{
i The 2008 Olympics bid for Beijing gave these organisations more importance. Two major 'genuine' popular organisations or NGOs, Global Village of Beijing and Friends of Nature, were co-opted to the official Olympics bid committee (Zhao, 2001).

ii For example, please see our work on www.asianphilanthropy.org providing philanthropy and third sector data and information on twelve Asia Pacific countries including all countries participated in this study. Also see Johns Hopkins Comparative Nonprofit Sector Project (http://www.jhu.edu/cnp/research/index.html), in particular data on India and the Philippines.

iii Particularly book three, chapter 9, article 1653. Before the existence of Civil Law it was regulated by the State Gazette (Stb) 1939 No.570 yo.717.

iv The mass organisations need to register with the Department of Home Affairs (if located in the capital city) or with the governor's office (for provincial cities) or with the regency government officer (in regency area) (Radyati and Fadjr, 2003).

' For example, many rules governing the TSOs are based on the respective high officials' speeches (Su, Ge, Zhang, and Gao, 1999, 43).

${ }^{v i}$ The new regulations in the Philippines would have been seen as too restrictive were it not for the largely positive atmosphere in which the GO-NGO interaction occurs (Carino, 2003).

vii The official documents, relevant to the regulation are explicit.On Feb. 26, 1998, the CCP Central Bureau and the MOCA issued a joint document regarding this.

viii The only exception Thailand seems to be creeping in.

ix The study uses data drawn from 14 unincorporated TSOs to provide insights into different process of governance practices, a study undertaken to understand the governance practices of unregistered initiatives in India by Third Sector Research Resource Centre (Unpublished.).
} 